\title{
Risk Factors Associated with Colorectal Cancer in Octogenarians Can Help Stratify the Need for Colonoscopy
}

\author{
Amy Y. Xiao ${ }^{10}$ Sulakchanan Anandabaskaran ${ }^{10}$ Maggie M. Ow ${ }^{1,2(0)}$ \\ ${ }^{1}$ Department of Medicine, University of Auckland, Auckland, \\ New Zealand \\ 2 Department of Gastroenterology and Hepatology, Auckland City \\ Address for correspondence Maggie M. Ow, MBChB, FRACP, MD, \\ Department of Medicine, University of Auckland, Private Bag 92019, \\ Auckland 1142, New Zealand (e-mail: m.ow@auckland.ac.nz). \\ Hospital, Auckland, New Zealand
}

J Coloproctol 2022;42(2):146-151.

\begin{abstract}
Keywords

- colonoscopy

- colorectal cancer

- elderly

- risk factors

Objective Colonoscopy is increasingly performed in octogenarians for the detection of colorectal cancer (CRC), but its benefits may be outweighed by its risks. The aim of the present study was to identify the risk factors for CRC in octogenarians presenting for colonoscopy to help stratify the need for this procedure.

Methods A retrospective analysis of 434 patients aged $\geq 80$ years referred for a colonoscopy between January 2018 and December 2019. Comparisons were made between those with and without CRC and advanced adenoma (AA). The primary endpoint was to identify the clinical variables predictive of CRC and $A A$, and the secondary endpoints were complications and death 30 days after the procedure. Results Colonoscopy was performed in 434 octogenarians, predominantly for symptoms, with CRC in 65 (15.0\%) patients. Iron deficiency was associated with a higher risk of having CRC identified on colonoscopy (odds ratio [OR]: 2.33; 95\% confidence interval $[95 \% \mathrm{Cl}]=1.36-4.00)$, but not symptoms such as bleeding, weight loss, or diarrhea. A colonoscopy in the last 10 years was protective, with a lower risk of CRC (OR: 0.45; 95\% $\mathrm{Cl}=0.22-0.93$ ). Patients with both normal iron stores and a colonoscopy within 10 years had a $92.5 \%$ chance of not having CRC. No variables were predictive of AA. Patients with complications, including death, were older and more likely to have underlying cardiorespiratory disease.

Conclusion Iron status and colonoscopy within 10 years can be used to predict the risk of CRC in octogenarians. Those with low predicted risk, especially if older and with cardiorespiratory disease, should be considered for non-invasive tests, such as computed tomography (CT) colonography, over colonoscopy.
\end{abstract}

received

September 7, 2021

accepted after revision

October 25, 2021

published online

January 31,2022
DOI https://doi.org/

10.1055/s-0041-1742256.

ISSN 2237-9363. (c) 2022. Sociedade Brasileira de Coloproctologia. All rights reserved.

This is an open access article published by Thieme under the terms of the Creative Commons Attribution-NonDerivative-NonCommercial-License, permitting copying and reproduction so long as the original work is given appropriate credit. Contents may not be used for commercial purposes, or adapted, remixed, transformed or built upon. (https://creativecommons.org/ licenses/by-nc-nd/4.0/)

Thieme Revinter Publicações Ltda., Rua do Matoso 170, Rio de Janeiro, RJ, CEP 20270-135, Brazil 


\section{Introduction}

Colorectal cancer (CRC) is the second leading cause of cancerrelated deaths globally, with 1.9 million new cases a year worldwide. ${ }^{1}$ The incidence of CRC increases with age, beginning around 40 years, ${ }^{2}$ and, with longer life expectancy, the number of colonoscopies in the elderly is rising rapidly in the Western world. Colonoscopy is the investigation of choice for the evaluation of lower gastrointestinal (GI) symptoms and detection of colorectal pathology. The symptoms and cases of serious pathology increase with age; therefore, the yield of colonoscopy, especially for colorectal neoplasia, also rises with increasing age. ${ }^{3}$ A study conducted in the United Kingdom with almost 1,000 colonoscopies in predominantly symptomatic patients reported a diagnostic yield for CRC of $20 \%$ in octogenarians, compared with $7.4 \%$ in those younger than 80 years of age. ${ }^{4}$ The benefit of a higher diagnostic yield of colonoscopy in the elderly, however, is offset by a shorter life expectancy in this group, ${ }^{5}$ higher frequency of comorbidities, ${ }^{6}$ and increased risk of adverse events and hospitalisations postprocedure. $^{7-10}$ It can also be technically more difficult to perform colonoscopy in the elderly, with lower completion rates and issues around inadequate bowel preparation. 2,11

Therefore, the decision to perform colonoscopy in patients of advanced age, especially the very elderly, requires careful consideration. Most studies ${ }^{12,13}$ on colonoscopy in the elderly have, to date, focused on diagnostic yield, technical factors, adverse events, and mortality. However, there is no data on who amongst the elderly is more likely to have an advanced colorectal neoplasm at the time of colonoscopy. This is an important consideration, especially in those who are frail or comorbid, as the benefit of colonoscopy may be outweighed by the potential risks if there is a low chance of an underlying CRC. The aim of the present study is to identify the risk factors associated with the presence of CRC in octogenarians undergoing colonoscopy.

\section{Methods}

We performed a retrospective study of all patients aged $\geq 80$ years who underwent colonoscopy for any indication at our tertiary institution between January 2018 and December 2019. The institutional Ethics in Research Committee approved the study prior to commencement, and informed consent was obtained from the participants.

All endoscopy data are entered into an electronic database using software developed to report endoscopy (Provation MD, Provation, Minneapolis, MN, US). The data included indication, comorbidities, sedation, tolerance, quality of the bowel preparationy, cecal intubation, endoscopic findings, therapeutics, withdrawal time, and complications. History of CRC or endoscopic procedures was also recorded.

The standard bowel preparation prior to colonoscopy at our unit was $3 \mathrm{~L}$ of polyethylene glycol, as a split-dose regimen. The option of having conscious sedation and the associated pros and cons were discussed with each patient, as part of the consent process. Conscious sedation was administered by the endoscopist using intravenous midazolam and fentanyl.
The level of tolerance was assessed by the endoscopist using the Modified Gloucester Comfort Score (MGCS): 1-none, talking comfortably throughout; 2-one or two episodes of mild discomfort, well tolerated; 3 -more than 2 episodes of discomfort, adequately tolerated; 4-significant discomfort experienced several times during the procedure; and 5-extreme discomfort frequently during the test. The quality of the bowel preparation was graded by the endoscopist as excellent; good; adequate; fair; or poor. The excellent, good, and adequate grades were considered acceptable preparation. The proximal extent reached was documented by photography. A complete examination was defined as visualisation and/or intubation of the ileocecal valve (or ileocolonic anastomosis in patients with previous resection).

\section{Study Endpoints}

All patients were followed up until 30 days postcolonoscopy or death, whichever came first. The primary endpoint was to identify the clinical variables associated with the occurrence of CRC and advanced adenomas (AAs) on colonoscopy. Advanced adenomas were defined as those with a diameter $\geq 10 \mathrm{~mm}$, with high-grade dysplasia or villous features on histology. The secondary endpoints were complications and death 30 days after the colonoscopy.

\section{Statistical Analysis}

The statistical analysis was performed using the Statistical Package for the Social Sciences (IBM SPSS Statistics for Windows, IBM Corp., Armonk, NY, US) software, version 26.0. The results were expressed as medians with interquartile ranges (IQRs), unless stated otherwise. The categorical data were compared using the Fisher exact test. Continuous data between patients with CRC/AA and patients without CRC/AA were compared using Mann-Whitney-U test. Univariate logistic regression analysis was performed to determine the variables associated with CRC. Multivariate logistic regression analysis was performed regarding the variables shown to be significant in the univariate analysis. For each variable, the odds ratio (OR) and $95 \%$ confidence interval $(95 \% \mathrm{CI})$ were calculated to determine the risk associated with CRC. The levels of statistical significance were determined by two-tailed tests $(p<0.05)$.

\section{Results}

A total of 4,733 colonoscopies were performed between January 1st, 2018, and December 31st, 2019, 434 (9.2\%) of which were in patients aged $\geq 80$ years. The clinical indications for colonoscopy are shown in - Table 1. The vast majority (97.9\%; $n=425 / 434$ ) of the patients were referred for symptomatic reasons. The most common indication was rectal bleeding. Prior to inclusion in the study, 32 patients had a history of colonic resection: 29 for previous CRC, 1 for Crohn disease, 1 for a large adenoma, and 1 for diverticular disease.

Of the 434 procedures, 399 (91.9\%) were performed under conscious sedation, with both intravenous midazolam and fentanyl administered in $92.5 \%(n=369 / 399)$ of sedated procedures, only midazolam in $1.8 \%(n=7 / 399)$ of sedated 
Table 1 Clinical indication for colonoscopy in 434 patients aged $\geq 80$ years

\begin{tabular}{|l|l|}
\hline Variable & $\begin{array}{l}\text { Number of } \\
\text { patients }=434\end{array}$ \\
\hline $\begin{array}{l}\text { Median age, years } \\
\text { (interquartile range) }\end{array}$ & $84(81-86)$ \\
\hline Male gender - $\mathrm{n}(\%)$ & $221(50.9)$ \\
\hline Clinical indication - $\mathrm{n}(\%)^{\mathrm{a}}$ & $145(33.4)$ \\
\hline $\begin{array}{l}\text { Iron deficiency with/ } \\
\text { without anemia }\end{array}$ & $87(20.0)$ \\
\hline Other anemia & $156(35.9)$ \\
\hline Rectal bleeding & $92(21.2)$ \\
\hline Diarrhea & $63(14.5)$ \\
\hline $\begin{array}{l}\text { Other changes in } \\
\text { bowel habits }\end{array}$ & $71(16.4)$ \\
\hline Abdominal pain & $81(18.7)$ \\
\hline Weight loss & $6(1.4)$ \\
\hline Polyp surveillance & $3(0.7)$ \\
\hline $\begin{array}{l}\text { Postcolorectal cancer } \\
\text { resection surveillance }\end{array}$ & $252(58.1)$ \\
\hline Outpatient procedure $-\mathrm{n}(\%)$ & \\
\hline
\end{tabular}

Notes: ${ }^{\mathrm{a}}$ Some patients had more than one indication. ${ }^{\mathrm{b}}$ Anemia without evidence of iron deficiency.

procedures, and only fentanyl in $5.8 \%(n=23 / 399)$ of sedated procedures. The median dose of midazolam was of $1.5 \mathrm{mg}$ (IQR: $1.0-2.0 \mathrm{mg}$ ), and the median dose of fentanyl was of 75 mcg (IQR: $50-100 \mathrm{mcg}$ ). Among those who were sedated, $97.0 \%(n=387 / 399)$ tolerated their colonoscopy very well (MGCS: $\leq 2$ ). The unsedated group also tolerated the procedure very well, with all but 1 patient with $\mathrm{MGCS} \leq 2$ (97.1\%; $\mathrm{n}=34 / 35)$. The quality of the bowel preparation was acceptable in $59.2 \%(n=257 / 434)$ of the procedures. The overall completion rate was of $90.3 \%(\mathrm{n}=391 / 434)$, and the adjusted completion rate (excluding obstructing lesions and poor preparation) was of $97.0 \%(n=421 / 434)$. The median withdrawal time (in procedures without maneuvres) was of 8.2 minutes (IQR: 6.4-11.1 minutes).

\section{Colorectal cancer and Advanced Adenoma}

Of the 434 patients, $15.0 \%(n=65 / 434)$ were diagnosed with CRC on colonoscopy. Three types of cancer other than CRC were detected: invasive prostate carcinoma, metastatic melanoma, and neuroendocrine carcinoma. A total of $15.7 \%$ $(n=68 / 434)$ of the patients had at least one AA: $12.2 \%$ $(\mathrm{n}=53 / 434)$ had an adenoma with a diameter $\geq 10 \mathrm{~mm}$; 9.9\% $(\mathrm{n}=43 / 434)$ had an adenoma with villous features; and $6.0 \%(\mathrm{n}=26 / 434)$ had an adenoma with high-grade dysplasia.

- Table 2 shows a comparison of the demographics and clinical characteristics of the patients with and without CRC. The univariate analysis (-Table 3 ) identified age, iron deficiency, and previous colonoscopy within 10 years as signifi-
Table 2 Comparison of 434 patients aged $\geq 80$ years stratified by the presence and absence of colorectal cancer on colonoscopy

\begin{tabular}{|l|l|l|l|}
\hline Variable & $\begin{array}{l}\text { With } \\
\text { CRC; } \\
\mathbf{n}=\mathbf{6 5}\end{array}$ & $\begin{array}{l}\text { Without } \\
\text { CRC; } \\
\mathbf{n}=369\end{array}$ & $p$-value \\
\hline $\begin{array}{l}\text { Median age, } \\
\text { years (IQR) }\end{array}$ & $85(82-87)$ & $83(81-86)$ & $\mathbf{0 . 0 4 8}$ \\
\hline Male gender & $33(50.8)$ & $188(50.9)$ & 1.000 \\
\hline Previous CRC & $4(6.2)$ & $25(6.8)$ & 1.000 \\
\hline $\begin{array}{l}\text { Iron deficiency with/ } \\
\text { without anemia }\end{array}$ & $33(50.8)$ & $112(30.4)$ & $\mathbf{0 . 0 0 2}$ \\
\hline Other anemia & $9(13.8)$ & $78(21.1)$ & 0.239 \\
\hline Rectal bleeding & $25(38.5)$ & $131(35.6)$ & 0.675 \\
\hline $\begin{array}{l}\text { Any changes in } \\
\text { bowel habits }\end{array}$ & $18(27.7)$ & $137(37.1)$ & 0.162 \\
\hline Diarrhea & $11(16.9)$ & $81(22.0)$ & 0.414 \\
\hline Abdominal pain & $12(18.5)$ & $59(16.0)$ & 0.589 \\
\hline Weight loss & $10(15.4)$ & $71(19.2)$ & 0.604 \\
\hline $\begin{array}{l}\text { Previous colonoscopy } \\
\text { within 10 years }\end{array}$ & $10(15.4)$ & $109(29.5)$ & $\mathbf{0 . 0 2 3}$ \\
\hline
\end{tabular}

Abbreviations: CRC, colorectal cancer; IQR, interquartile range. Notes: Values are expressed as numbers and percentages, unless stated otherwise. ${ }^{\mathrm{a}}$ Anemia without evidence of iron deficiency.

cant variables predicting CRC on colonoscopy. On the multivariate analysis (-Table $\mathbf{3}$ ), only iron deficiency and colonoscopy within 10 years were significant predictors of CRC. Iron deficiency was independently associated with an almost 2.5-fold increase in risk (OR: $2.33 ; 95 \% \mathrm{CI}=1.36-4.00$; $p=0.002$ ). In contrast, a previous colonoscopy within 10 years was associated with halving of the risk of CRC (OR: $0.45 ; 95 \% \mathrm{Cl}=0.22-0.93 ; p=0.031$ ). Patients with both normal iron stores and a colonoscopy within 10 years had a $92.5 \%$ chance of not developing CRC.

However, none of the clinical variables in - Table 2 were associated with the presence of AAs.

\section{Complications and Mortality}

Patients who developed complications, including death, were significantly older and more likely to have underlying cardiorespiratory disease (-Table 4). Intraprocedural factors, such as patient tolerance, the sedation used, or the quality of the bowel preparation were not significant.

At 30 days, 19 (4.4\%) patients developed a complication there were 6 cardiac events, 4 cases of bleeding, 4 falls (with 2 fractures of the neck of the femur), 3 cases of pneumonia, 1 case of dehydration, 1 stroke, 1 urinary retention, and 1 perforation. In total, 1 patient had 3 complications, 7 (1.6\%) died within 30 days of the colonoscopy -2 following their operations for fracture of the neck of the femur, 1 , from stroke, 1 , from ischemic colitis (the presenting complaint), and 3 , from their underlying cancers (1 colorectal, 1gastric, 1 pancreatic). 
Table 3 Univariate and multivariate analysis of colorectal cancer on colonoscopy in patients aged $\geq 80$ years

\begin{tabular}{|c|c|c|c|c|}
\hline \multirow[t]{2}{*}{ Variable } & \multicolumn{2}{|l|}{ Univariate analysis } & \multicolumn{2}{|c|}{ Multivariate analysis } \\
\hline & OR $(95 \% \mathrm{Cl})$ & $p$-value & OR $(95 \% \mathrm{Cl})$ & $p$-value \\
\hline Age (years) & $1.07(1.00-1.15)$ & 0.050 & $1.06(0.98-1.14)$ & 0.157 \\
\hline Male gender & $0.99(0.59-1.68)$ & 0.979 & & \\
\hline Previous colorectal cancer & $0.90(0.30-2.68)$ & 0.853 & & \\
\hline Iron deficiency with/without anemia & $2.37(1.39-4.04)$ & 0.002 & $2.33(1.36-4.00)$ & 0.002 \\
\hline Other anemia ${ }^{a}$ & $1.61(0.94-2.76)$ & 0.084 & & \\
\hline Rectal bleeding & $1.14(0.66-1.96)$ & 0.647 & & \\
\hline Any changes in bowel habit & $0.60(0.33-1.08)$ & 0.091 & & \\
\hline Diarrhea & $0.72(0.36-1.45)$ & 0.362 & & \\
\hline Abdominal pain & $0.88(0.41-1.88)$ & 0.740 & & \\
\hline Weight loss & $0.68(0.32-1.43)$ & 0.303 & & \\
\hline Previous colonoscopy within 10 years & $0.43(0.21-0.88)$ & 0.021 & $0.45(0.22-0.93)$ & 0.031 \\
\hline
\end{tabular}

Abbreviations: $95 \% \mathrm{Cl}$, 95\% confidence interval; OR, odds ratio.

Note: ${ }^{\mathrm{a} A n e m i a}$ without evidence of iron deficiency.

Table 4 Comparison of patients aged $\geq 80$ years with and without complications, including death up to 30 days after the colonoscopy

\begin{tabular}{|l|l|l|l|}
\hline Variable & $\begin{array}{l}\text { No complications; } \\
\mathbf{n}=\mathbf{4 1 2}\end{array}$ & $\begin{array}{l}\text { All complications, including death; } \\
\mathbf{n}=\mathbf{2 2}\end{array}$ & $\boldsymbol{p}$-value \\
\hline Median age, years (IQR) & $83(81-86)$ & $86(84-88)$ & 0.007 \\
\hline Male gender & $210(51.0)$ & $11(50.0)$ & 1.000 \\
\hline Outpatient procedure & $243(59.0)$ & $9(40.9)$ & 0.120 \\
\hline Median dose of midazolam, mg (IQR) & $1.5(1.0-2.0)$ & $1.3(0.5-2.1)$ & 0.996 \\
\hline Median dose of fentanyl, mcg (IQR) & $75(50-100)$ & $75(50-100)$ & 0.342 \\
\hline Median patient tolerance, MGCS (IQR) & $1.0(1.0-1.0)$ & $1.0(1.0-2.0)$ & 0.406 \\
\hline Acceptable bowel preparation & $244((59.2)$ & $13(59.1)$ & 1.000 \\
\hline Comorbidities & & & \\
\hline Cardiorespiratory disease & $170(41.3)$ & $14(63.6)$ & 0.047 \\
\hline Diabetes & $83(20.1)$ & $5(22.7)$ & 0.786 \\
\hline Stroke & $53(12.9)$ & $3(13.6)$ & 1.000 \\
\hline Cognitive impairment/dementia & $31(7.5)$ & $3(13.6)$ & 0.402 \\
\hline Renal replacement therapy & $5(1.2)$ & $0(0.0)$ & 1.000 \\
\hline Other active (non-CRC) cancers & $32(7.8)$ & $3(13.6)$ & 0.407 \\
\hline
\end{tabular}

Abbreviations: CRC, colorectal cancer; IQR, interquartile range; MGCS, Modified Gloucester Comfort Score.

Notes: Values are expressed as numbers and percentages, unless stated otherwise. ${ }^{a}$ See the Methods section for the MGCS scoring criteria.

\section{Discussion}

Colonoscopy in the very elderly is a clinical decision that requires careful evaluation, with factors such as patient tolerance, risk of complications, and coexisting comorbidities contributing to this decision. ${ }^{14}$ The readily-available alternative, computed tomography (CT) colonography (CTC), is increasingly used in this population due to its easy preparation, better patient tolerance, and good safety profile, without any of the risks associated with sedation and invasive procedures. ${ }^{15}$ Nevertheless, serious pathology is prevalent in this age group, and it is important to be able to identify the patients most likely to develop CRC, as this subgroup requires tissue diagnosis in a timely fashion, and it is best that they proceed straight to colonoscopy. To our knowledge, the present is the first study to report on the clinical predictors of CRC on colonoscopy in the elderly. Our cohort consists of patients who are extremely elderly, as this is an age group that is not often included in studies on colonoscopy but in whom management can be particularly challenging.

In our population of octogenarians, the vast majority underwent colonoscopy for symptomatic indications, and 
the diagnostic yield for CRC was high, as expected: $15.0 \% .^{3,4,11,12,16-18}$ We found that patients with iron deficiency and those who did no undergo a colonoscopy in the last 10 years were significantly more likely to have a diagnosis of CRC on colonoscopy. Iron-deficiency anemia is recognised as a marker of occult GI malignancy. The prevalence of CRC in individuals with iron deficiency varies, with higher rates in men and postmenopausal women and in those with concurrent GI symptoms. ${ }^{19}$ The present study confirmed that iron deficiency is an important risk factor for CRC in the very elderly, and this is independent of any GI symptoms. Interestingly, none of the symptoms, such as bleeding or diarrhea, was independently associated with CRC. Rectal bleeding was the most common indication for colonoscopy in the present study, and is often described as a red flag for CRC. In our population, however, rectal bleeding was not predictive of CRC. This may be because hematochezia is often due to diverticular disease in this age group, which is a highly-prevalent condition, affecting over $60 \%$ of octogenarians, ${ }^{20}$ and may not be specific enough as a risk factor for CRC.

In the present study, a colonoscopy in the last 10 years was protective and found to be a negative predictor of CRC: patients with a previous colonoscopy had half the risk of developing CRC compared to those who had not had a colonoscopy within 10 years. This is consistent with previous data from case-control and population studies documenting a reduced risk of CRC over a 10 -year period in individuals who had a negative colonoscopy. ${ }^{21}$ In our population, around one third of patients had had a colonoscopy in the last 10 years, and this subgroup, especially if iron stores are normal as well, have a relatively low risk of having a diagnosis of CRC on colonoscopy, with $92.5 \%$ having only benign pathologies found. Therefore, it is better to submit this subgroup to a non-invasive test, such as a CTC, as their initial investigation, which is safer and better tolerated than colonoscopy, and with similar detection rates for large polyps and CRC. $^{15}$

An important difference between the present study and many of the previous studies on colonoscopy in the very elderly is that our cohort comprised a large proportion of inpatients. Elderly inpatients are acutely unwell, may be more comorbid or deconditioned, and this may influence factors such as bowel preparation, procedure tolerance, and safety outcomes. In the present study, almost $40 \%$ of octogenarians had unacceptable bowel preparation, somewhat higher than the $15 \%$ to $25 \%$ reported in other studies. ${ }^{12}$ Having said this, our cohort had a very respectable completion rate (unadjusted: 90\%; adjusted: 97\%), which is comparable to published data on this population, ${ }^{12}$ despite issues with bowel preparation. Patient comfort during the procedure also rated well, with $97 \%$ reporting no more than 1 or 2 episodes of mild discomfort. With respect to complications, the risks of perforation, bleeding, and cardiorespiratory events in the present study were comparable to those of previous reports. ${ }^{22,23}$ Older patients and those with underlying cardiorespiratory disease were more likely to develop a complication, including death. We also observed a higher mortality rate (1.6\%) in our cohort compared to those of other studies, in which the incidence of mortality at 30 days is reported to be of approximately 1 to 5 per 1,000 colonoscopies. ${ }^{7}$ This increased mortality may be due to a higher proportion of inpatients in the present study, and further emphasizes the importance of careful evaluation when deciding in whom to perform a colonoscopy.

There are limitations to the present study. First, it was a retrospective study, and, as so, at risk of selection bias, as the patients studied may have been those who were more physically fit to undergo colonoscopy. Nevertheless, our data can help inform clinicians when making decisions on requesting colonoscopy in the elderly. Second, the cohort represents a sample from a tertiary centre, which introduces referral bias and limits the generalizability of the data to some extent. There is likely to be a greater representation of inpatients with complex medical problems requiring tertiary level care in our cohort. Thirdly, the quality of the bowel preparation was not measured using a validated quantitative scale such as the Boston Bowel Preparation score. Lastly, as the study was retrospective, only complications that required presentation to hospital or that were reported by the patient to the endoscopy unit would be recorded, and minor adverse events may not have been captured. Notwithstanding this, patients are given postprocedure instructions, which include a list of symptoms to look out for and recommendations to contact the endoscopy unit if these occur; hence, serious complications would have been accurately captured.

\section{Conclusion}

In summary, colonoscopy in octogenarians has a high diagnostic yield for CRC, and several clinical factors are useful to help stratify which patient has a greater risk of having a CRC at presentation, and therefore should proceed straight to colonoscopy. Octogenarians referred with iron deficiency, especially if they have not had a colonoscopy in the last 10 years, are at the highest risk of having a CRC, and should be strongly considered for colonoscopy. Conversely, those who have normal iron stores and have had a colonoscopy in the last 10 years should be considered for a non-invasive test, such as CTC, first, especially if they are older octogenarians and have underlying cardiorespiratory disease, as they have a low chance of having CRC and are more likely to suffer a complication after the colonoscopy. Colonoscopy is generally safe, with few adverse events, but does carry a risk of death, which is not inconsiderable. Therefore, prior to any decision to attempt colonoscopy in a very elderly patient, a careful assessment should include an evaluation of the aforementioned clinical predictors to determine the likelihood of detecting a CRC. Further prospective multi-centre studies are needed to validate the findings of the present study.

\section{Disclosure Statement}

This research did not receive any specific grants from funding agencies in the public, commercial, or not-forprofit sectors.

\section{Conflict of Interests}

The authors have no conflict of interests to declare. 


\section{References}

1 Ferlay J, Ervik M, Lam F, et al. Global Cancer Observatory: Cancer Today. Lyon, France: International Agency for Research on Cancer Accessed February 2021 from: https://gco.iarc.fr/today

2 Lukens FJ, Loeb DS, Machicao VI, Achem SR, Picco MF. Colonoscopy in octogenarians: a prospective outpatient study. Am J Gastroenterol 2002;97(07):1722-1725

3 Stevens T, Burke CA. Colonoscopy screening in the elderly: when to stop? Am J Gastroenterol 2003;98(08):1881-1885

4 Arora A, Singh P. Colonoscopy in patients 80 years of age and older is safe, with high success rate and diagnostic yield. Gastrointest Endosc 2004;60(03):408-413

5 Wilson JA. Colon cancer screening in the elderly: when do we stop? Trans Am Clin Climatol Assoc 2010;121:94-103

6 Kahi CJ, Azzouz F, Juliar BE, Imperiale TF. Survival of elderly persons undergoing colonoscopy: implications for colorectal cancer screening and surveillance. Gastrointest Endosc 2007;66 (03):544-550

7 Day LW, Kwon A, Inadomi JM, Walter LC, Somsouk M. Adverse events in older patients undergoing colonoscopy: a systematic review and meta-analysis. Gastrointest Endosc 2011;74(04): 885-896

8 Costa-Moreira P, Silva M. Screening Colonoscopy in Older Patients: Elder Care or Elder Abuse? Dig Dis Sci 2020;65(07): 1874-1876

9 Grossberg LB, Papamichael K, Leffler DA, Sawhney MS, Feuerstein JD. Patients over Age 75 Are at Increased Risk of Emergency Department Visit and Hospitalization Following Colonoscopy. Dig Dis Sci 2020;65(07):1964-1970

10 Tran AH, Man Ngor EW, Wu BU. Surveillance colonoscopy in elderly patients: a retrospective cohort study. JAMA Intern Med 2014;174(10):1675-1682

11 Cha JM, Kozarek RA, La Selva D, et al. Risks and benefits of colonoscopy in patients 90 years or older, compared with younger patients. Clin Gastroenterol Hepatol 2016;14(01):80-6.e1

12 Lin OS. Performing colonoscopy in elderly and very elderly patients: Risks, costs and benefits. World J Gastrointest Endosc 2014;6(06):220-226
13 Travis AC, Pievsky D, Saltzman JR. Endoscopy in the elderly. Am J Gastroenterol 2012;107(10):1495-1501, quiz 1494, 1502

14 Maratt JK, Calderwood AH. Colorectal cancer screening and surveillance colonoscopy in older adults. Curr Treat Options Gastroenterol 2019;17(02):292-302

15 Kim DH, Pickhardt PJ, Taylor AJ, et al. CT colonography versus colonoscopy for the detection of advanced neoplasia. N Engl J Med 2007;357(14):1403-1412

16 Virk GS, Jafri M, Ashley C. Colonoscopy and colorectal cancer rates among octogenarians and nonagenarians: nationwide study of US veterans. Clin Interv Aging 2019;14:609-614

17 Karajeh MA, Sanders DS, Hurlstone DP. Colonoscopy in elderly people is a safe procedure with a high diagnostic yield: a prospective comparative study of 2000 patients. Endoscopy 2006;38(03):226-230

18 Loffeld RJ, Liberov B, Dekkers PE. Yearly diagnostic yield of colonoscopy in patients age 80 years or older, with a special interest in colorectal cancer. Geriatr Gerontol Int 2012;12(02): 298-303

19 Ioannou GN, Rockey DC, Bryson CL, Weiss NS. Iron deficiency and gastrointestinal malignancy: a population-based cohort study. Am J Med 2002;113(04):276-280

20 Lorenzo D, Gallois C, Lahmek P, et al; Groupe des Hémorragies Digestives Basses de l'ANGH (Association Nationale des HépatoGastroentérologues des Hôpitaux Généraux) Middle-term mortality and re-bleeding after initial diverticular bleeding: A nationwide study of 365 mostly elderly French patients. United European Gastroenterol J 2017;5(01):119-127

21 Singh H, Turner D, Xue L, Targownik LE, Bernstein CN. Risk of developing colorectal cancer following a negative colonoscopy examination: evidence for a 10 -year interval between colonoscopies. JAMA 2006;295(20):2366-2373

22 Causada-Calo N, Bishay K, Albashir S, Al Mazroui A, Armstrong D. Association Between Age and Complications After Outpatient Colonoscopy. JAMA Netw Open 2020;3(06):e208958

23 Clarke GA, Jacobson BC, Hammett RJ, Carr-Locke DL. The indications, utilization and safety of gastrointestinal endoscopy in an extremely elderly patient cohort. Endoscopy 2001;33(07):580-584 